\title{
The inevitable contrast: Conscious vs. unconscious processes in action control
}

\author{
Ezequiel Morsella ${ }^{1,2 *}$ and T. Andrew Poehlman ${ }^{3}$ \\ ${ }^{1}$ Department of Psychology, San Francisco State University, San Francisco, CA, USA \\ 2 Department of Neurology, University of California, San Francisco, San Francisco, CA, USA \\ ${ }^{3}$ Marketing Department, Cox School of Business, Southern Methodist University, Dallas, TX, USA \\ *Correspondence: morsella@sfsu.edu
}

Edited by:

Lorenza S. Colzato, Leiden University, Netherlands

Keywords: action, consciousness, unconscious processing, voluntary action, perception-and-action

The simple actions of everyday life-flicking a light switch, suppressing the urge to say something, or grabbing a waiter's attention with a "check, please"-remain difficult to understand from a scientific point of view. Unlike the mechanisms giving rise to machine action-which are designed according to clearcut, well principled plans- the mechanisms underlying human action are fashioned by the happenstance and tinkering process of evolution, whose products can be counterintuitive and suboptimal (Simpson, 1949; Lorenz, 1963; Gould, 1977; de Waal, 2002; Marcus, 2008), far unlike the kinds of things we humans design into robots (Arkin, 1998) ${ }^{1}$. When speaking about the reverse engineering of biological products, the roboticist thus cautions, "Biological systems bring a large amount of evolutionary baggage unnecessary to support intelligent behavior in their silicon based counterparts" (Arkin, 1998, p. 32), and, speaking of the products of mother nature, the ethologist concludes, "To the biologist who knows the ways in which selection works and who is also aware of its limitations it is no way surprising to find, in its constructions, some details which are unnecessary or even detrimental to survival" (Lorenz, 1963, p. 260).

Faced with this and many other challenges (cf., Rosenbaum, 2005; Herwig et al., 2013), the student of human action is forced to abandon a normative view (which describes how things should function) of the phenomena at hand and adopt instead a more humble, descriptive view (which describes the products of nature as they have evolved to be). From such a descriptive approach, investigators over the past two decades have begun to illuminate, not only the basic processes underlying human action, but the liaison between action and consciousness- the most mysterious aspect of nervous function (Roach, 2005).

In this special issue of Frontiers in Cognition, we survey these advances stemming from disparate fields of inquiry, including cognition, neuroscience, and artificial intelligence/robotics. Together, these developments unveil a great deal about the links between perception and action while also illuminating much about all else in between. Of note, these developments also reveal that the study of action production and control ("action control," for short) provides a unique portal through which to examine the nature of conscious processing. As explained below, many aspects of consciousness are easier to study from

\footnotetext{
${ }^{1}$ Consider that the artificial heart is very different from its natural counterpart and that the difference between human locomotion and artificial locomotion is a stark one-that between legs versus wheels.
}

an action-based approach than from a perception-based perspective, which has been the traditional approach to studying consciousness (e.g., Crick and Koch, 2003; see discussion in Baars, 1997).

Before discussing further the liaison between consciousness and action control, and what the latter informs about the former, it is important to first describe the most nebulous term at hand, "consciousness."

\section{THE MIND-BOGGLING AND (UNFORTUNATELY) INESCAPABLE PROBLEM OF CONSCIOUSNESS AND THE BRAIN}

Throughout intellectual history, people have been investigating the phenomenon of consciousness in one way or another, though often while avoiding utterance of the controversial term, "consciousness," which has been considered unscientific for most of its history. During the Behaviorist era (1919-1948), in which discussion of consciousness was strongly discouraged, the rank and file psychophysicist and Gestalt psychologist continued to study the "conscious field" that had been the object of investigation during the earlier Structuralist era pioneered by Wundt and Titchener (1879-1919). Since the fall of Behaviorism, a de facto distinction has been made between conscious and unconscious processing in every field of inquiry of psychology and neuroscience, though, again, often without mention of the term "consciousness." In perception research, psychophysical measurement continues to make the distinction of supra- vs. subliminal, and to base its conclusions on conscious "self-report." In the study of attention, the term "attentional awareness" is often contrasted with unconscious, "pre-attentive" processing (Treisman and Gelade, 1980). In memory research, there is the classic distinction between "declarative" (explicit) processes and "procedural" (implicit) processes (Squire, 1987; Schacter, 1996). In research on motor control and on language production, the conscious aspects of voluntary action and action monitoring are contrasted with the unconscious aspects of motor programming (Levelt, 1989; Rosenbaum, 2002), including the implicit learning of motor sequences (Taylor and Ivry, 2013). Last, various fields contrast "controlled" processing, which tends to be associated with consciousness, and "automatic" processing, which tends to be associated with unconscious mechanisms (e.g., Lieberman, 2007; but see Panagiotaropoulos et al., 2013).

In summary, the difference between conscious and unconscious processes (regardless of the appellations ascribed to each 
process) is an inescapable contrast that is encountered after even a cursory examination of mental and nervous phenomena ${ }^{2}$.

Upon accepting that, in the natural world, there are conscious and unconscious processes, then one must contemplate the phenomenon of consciousness. Understanding how the nervous system gives rise to basic, low-level consciousness-the subjective experience of pain, breathlessness, or a yellow afterimageremains one of the greatest puzzles in science (Crick, 1995; Roach, 2005). This most basic form of consciousness is referred to as "sentience" (Pinker, 1997), "subjective experience," "phenomenal state," and "qualia" (Gray, 2004). It has been best defined by Nagel (1974), who proposed that an organism possesses consciousness if there is something it is like to be that organism-something it is like, for example, to be human and experience pain, yellow afterimages, or breathlessness.

Some have attempted to explain away this mind-boggling puzzle by claiming that consciousness does not exist (which is perhaps the least deniable fact of our existence, given that consciousness encompasses the totality of all we know) or that it exists but serves no function (that is, it is "epiphenomenal") in the nervous system. Unfortunately, while the former view is difficult to defend, the latter view does not provide an escape from the enigma at hand either. Regardless of whether consciousness serves a function in the nervous system or not, the scientist must still explain its place within nature: Huxley's steam whistle may be epiphenomenal with respect to the locomotive, but the scientist must still understand what it is (high frequencies) and how it arises from physical events (high pressured steam released through a small aperture). It seems premature to state that a phenomenon does not serve a function when the place of that phenomenon within nature remains unknown. In short, even if a phenomenon is functionless, a complete scientific account of the natural world must include an explication of it. See, in this issue, the article by Pereira et al. for a novel, untraditional approach to consciousness; see also relevant articles by Cruse and Schilling, by Hommel, and by Masicampo and Baumeister.

Progress regarding the puzzle of consciousness has stemmed from descriptive approaches juxtaposing conscious and unconscious processing in terms of their cognitive and neural correlates (Shallice, 1972; Logothetis and Schall, 1989; Crick and Koch, 1995; Kinsbourne, 1996; Wegner and Bargh, 1998; Grossberg, 1999; Di Lollo et al., 2000; Dehaene and Naccache, 2001; Baars, 2002, 2005; Gray, 2004; Libet, 2004; Laureys, 2005; Morsella, 2005; Merker, 2007; Doesburg et al., 2009; Damasio, 2010; Boly et al., 2011; Panagiotaropoulos et al., 2012). [For a review regarding the conclusions of this contrast, see Godwin et al. (2013); for discussion of the limitations of a contrastive approach, see Aru et al. (2012).] To examine this contrast, researchers have focused primarily on perceptual processing (see Panagiotaropoulos et al., 2013), for several important reasons

\footnotetext{
${ }^{2}$ It is important to appreciate that, even in the early Twentieth Century, in the field of psychiatry (which was at that time independent from psychophysics and other forms of academic psychology), the student of the mind realized that in the nervous system there are processes that are consciously mediated and those that are unconsciously mediated, as discussed at length and with great insight by the psychiatrist Bleuler (1924).
}

(see reasons in Crick and Koch, 2003). Perception-based research has illuminated how entry into consciousness ("entry," for short) is influenced by processes that are "bottom-up" (e.g., stimulus salience, motion, novelty, incentive and emotional quality, etc.; Gazzaley and D'Esposito, 2007) or attentional (cf., Most et al., 2005). This important research has led to several advances (see review in Koch, 2004), including (a) the differences in the processing of stimuli that are supraliminal (i.e., consciously-perceptible) and subliminal (i.e., consciously-imperceptible; Logothetis and Schall, 1989; Dehaene and Naccache, 2001; Koch, 2004; Roser and Gazzaniga, 2004; Doesburg et al., 2009), and (b) uncovering the unconscious processes preceding a conscious percept (Di Lollo et al., 2000; Goodhew et al., 2012; see Fischer et al., 2013).

Such research has also led to the integration consensus (Tononi and Edelman, 1988; Baars, 1988, 1998, 2005, 2013; Damasio, 1989; Freeman, 1991; Srinivasan et al., 1999; Zeki and Bartels, 1999; Edelman and Tononi, 2000; Dehaene and Naccache, 2001; Llinás and Ribary, 2001; Varela et al., 2001; Clark, 2002; Ortinski and Meador, 2004; Sergent and Dehaene, 2004; Morsella, 2005; Del Cul et al., 2007; Kriegel, 2007; Merker, 2007; Doesburg et al., 2009; Uhlhaas et al., 2009; Boly et al., 2011; Koch, 2012; TallonBaudry, 2012; Tononi, 2012), which proposes that consciousness integrates neural activities and information-processing structures that would otherwise be independent (see reviews in Baars, 2002; see Morsella, 2005, for the limitations of the integration consensus and for a listing of integrations that can occur unconsciously). Findings from action-based research complement the integration consensus: Consistent with the integration consensus, in conditions in which actions are decoupled from consciousness (e.g., in neurological disorders), actions often appear impulsive or inappropriate, as if they are not adequately influenced by the kinds of information by which they should be influenced (Morsella and Bargh, 2011). These actions reveal a lack of adequate integration. Thus, consciousness appears to permit a form of integration that constrains potential action, achieving a form of multiple-constraint satisfaction (Merker, 2013). Constraints can be "online," reflecting stimuli in the current environment, or they can be "offline," reflecting covert processes such as memory, cognitive maps, operations on mental representations, and mental simulation (Schacter and Addis, 2007). For example, recent theories propose that the function of explicit, episodic memory-a form of knowledge representation intimately associated with the past-is actually to simulate future, potential actions (Schacter and Addis, 2007).

\section{CONSCIOUSNESS AND ACTION}

Although theorists have long appreciated that consciousness is intimately related to action (James, 1890; Neumann, 1987; Allport, 1989; Hamker, 2003; Morsella, 2005; Baddeley, 2007), until recently there has been a substantial gap in our knowledge regarding how action-related processes influence consciousness. The reason for this gap is not surprising, as action itself is an under-explored topic of research (see reasons for this in Nattkemper and Ziessler, 2004; Rosenbaum, 2005; Agnew et al., 2009; Herwig et al., 2013). Action control is a highly complicated process, one involving various kinds of mechanisms (e.g., hierarchical vs. distributed control and forward modeling vs. inverse 
modeling; Arkin, 1998; Miall, 2003). See in this issue, the article by Jordan. Only recently have researchers begun to focus on the action-related aspects of consciousness (e.g., Frith et al., 2000; Lau et al., 2004; Libet, 2004; Morsella, 2005; Berti and Pia, 2006; Jeannerod, 2006; Pacherie, 2008; Morsella and Bargh, 2010).

The following sections summarize those findings from actionbased research that are relevant to this special issue about consciousness and action control (for a review of all action research, see Morsella, 2009) ${ }^{3}$.

\section{UNCONSCIOUS PROCESSING IN ACTION CONTROL}

Investigations on consciousness and action control have revealed that many sophisticated aspects of action production can or do occur unconsciously (Bargh and Morsella, 2008; Morsella and Bargh, 2011; see Panagiotaropoulos et al., 2013). Specifically, investigations from diverse areas (see review in Morsella and Bargh, 2011), including motor control (Rosenbaum, 2002), subliminal processing (Hallett, 2007), automatisms (Morsella and Bargh, 2011), dissociations between action and conscious perception (Goodale and Milner, 2004), and the automatic activation of action plans (Morsella and Miozzo, 2002; Ellis, 2009), reveal that the activation, modulation, selection, and, in some cases, expression of action plans can occur unconsciously. For example, research on various neurological conditions has revealed aspects of action control that can occur unconsciously. These neurological conditions include blindsight (Weiskrantz, 1992, 1997), blind smell (Sobel et al., 1999), utilization behavior (Lhermitte, 1983), visual form agnosia (e.g., Patient D. F.; Milner and Goodale, 1995), anarchic hand syndrome (Marchetti and Della Sala, 1998), sensory neglect (Graziano, 2001; Heilman et al., 2003), unintentional ambient echolalia (Suzuki et al., 2012), and complex automatisms, (e.g., vocalizations and singing) during epileptic seizures (Blanken et al., 1990; Enatsu et al., 2011; Kececi et al., 2013). Insights about consciousness and action control stemmed also from the study of the "split brain" patient (Sperry, 1961), and from conditions in which declarative memory is compromised but action programs can be stored and influence action even when the patient is unaware of the acquisition or maintenance of these programs (e.g., as in the case of H. M.; Milner, 1966). Together, this research provided substantial knowledge about the sophisticated capacities of unconscious processing in action control (see, in this issue, contributions by Cruse and Schilling, by Fischer et al., by Hommel, by Masicampo and Baumeister, by Panagiotaropoulos et al., and by Merker).

This research also reveals which aspects of action control may be unconscious during normal, everyday action, in which conscious and unconscious processes interact in ways that are only now beginning to be understood (see, in this issue, articles by Lynn et al., by Panagiotaropoulos et al., and by Merker). For instance, under normal circumstances, a person is unconscious of the complicated motor programs that, during action production, calculate which muscles should be activated at a given time (James, 1890; Rosenbaum, 2002; Johnson and Haggard, 2005; see Grossberg, 1999, about why motor programs must be

${ }^{3}$ The following is based in part on reviews of the literature presented in Morsella and Bargh (2011); Morsella et al. (2011) and Hubbard et al. (2013). unconscious). Specifically, evidence suggests that one is unconscious of the programming of the efference to the muscles as well as of the adjustments that are made "online" as one, say, reaches for a moving object (Fecteau et al., 2001; Rossetti, 2001; Rosenbaum, 2002; Goodale and Milner, 2004; Heath et al., 2008; Liu et al., 2008; see, in this issue, articles by Anderson et al. and by Rosenbaum et al.).

The activation of action plans (a phenomenon to be distinguished from motor control) can occur unintentionally (see Lynn et al., this issue). This has been revealed in experimental paradigms in which the mere presence of incidental action-related stimuli can interfere with one's intended response to a target stimulus. A basic form of this effect has been demonstrated for decades in the classic Stroop task (Stroop, 1935; see reviews in MacLeod and Dunbar, 1988; MacLeod, 1991; MacLeod and MacDonald, 2000), in which the mere presence of a word (e.g., RED) interferes with naming a patch of color (e.g., blue). In this task, participants are instructed to name the color in which a word is written. When the color matches the word (e.g., RED presented in red), or is presented on a neutral stimulus (e.g., a series of x's as in XXXX), there is little or no interference [e.g., decreased response times (RTs)] and decreased perturbations in consciousness (e.g., "urges to make a mistake"; Morsella et al., 2009a). (Urges to err, a subjective effect, are obtained simply by asking participants after each trial, "How strong was your urge to make a mistake?" which participants rate on an 8-point scale, in which 1 signifies "almost no urge" and 8 signifies "extremely strong urge.") When the word and color are incongruous (e.g., RED presented in blue), response conflict leads to interference (Cohen et al., 1990), including increased RTs, error rates, and systematic changes in consciousness, such as urges to err (Morsella et al., 2009a).

In the incongruent condition, set-related top-down activation from prefrontal cortex increases the activation of areas in posterior brain regions (e.g., visual association cortex) that are associated with task-relevant dimensions (e.g., color; Enger and Hirsch, 2005; Gazzaley et al., 2005). Thus, to influence behavior, action sets from information in working memory or long-term memory increase or decrease the strength of perceptuosemantic information, along with, most likely, other kinds of information (e.g., motor priming). The finding that top-down activation strengthens one representation (e.g., color-naming) over another (e.g., word-reading) can be characterized as a case of "refreshing," the act of foregrounding one representation over another (Johnson and Johnson, 2009). Following an incongruent trial, ramped up activation in control regions of the brain (e.g., the dorsolateral prefrontal cortex) leads to improved performance on the subsequent trial (Cohen et al., 1990).

\section{PARADIGMS ILLUMINATING THE LIAISON BETWEEN CONSCIOUSNESS AND ACTION CONTROL}

The Stroop task is one of many response interference paradigms (see, in this issue, articles by Anguera et al. and by Lynn et al.). In such paradigms, subjects attempt to respond to a target (e.g., font color in the Stroop task) while presented with a distractor (e.g., Stroop word). Such interference paradigms have revealed much about the role of consciousness in action control. Findings 
complementing that of the Stroop paradigm have been obtained with the classic Eriksen flanker task (Eriksen and Eriksen, 1974). In one version of the task (Eriksen and Schultz, 1979), participants are trained to press one button with one finger when presented with the letter $\mathrm{S}$ or $\mathrm{M}$ and to press another button with another finger when presented with the letter $\mathrm{P}$ or $\mathrm{H}$. After training, participants are then instructed to respond to the stimulus presented in the center of an array (e.g., SSPSS, SSMSS, targets underscored) and to disregard the "flanking" distractors (i.e., the Ss). Of all the flanker conditions, measures of interference such as RTs, error rates, and self-reported urges to err are lowest in the Identical condition, where flankers and targets are identical, as in SSSSS (Eriksen and Schultz, 1979; Morsella et al., 2009b). In this paradigm, it is well-established that interference is greater when distractors are associated with a response that is different from that of the target (response interference; e.g., SSPSS) than when distractors look different from targets but are associated with the same response (perceptual interference; e.g., SSMSS; van Veen et al., 2001; Morsella et al., 2009b). These findings, revealing that perceptual processes can automatically activate action plans, have been used as evidence for continuous flow (Eriksen and Schultz, 1979) and cascade (McClelland, 1979; Navarrete and Costa, 2004) models of perception-and-action (see discussion in Morsella, 2009; see, in this issue, Filevich and Haggard's treatment of the effects of unselected actions).

There are many other experimental paradigms that illuminate the study of consciousness and action control: the anti-saccade task (Hallett, 1978; Curtis and D'Esposito, 2009), the MacLeod and Dunbar object naming task (MacLeod and Dunbar, 1988), spatial compatibility tasks (e.g., the Simon task; Simon et al., 1970), response-effect compatibility paradigms (Kunde, 2001), the Posner attentional cuing task (1980), dual-task paradigms (Kahneman, 1973; Logan and Gordon, 2001), binocular rivalry (Alais and Blake, 2005), inattentional blindness (Raymond et al., 1992), covert priming paradigms (Bargh and Chartrand, 2000), the implicit association task (Greenwald et al., 1998), and the go/no go (Newman et al., 1985) and stop-signal tasks (Lappin and Eriksen, 1966; see, in this issue, articles by Anguera et al. and by Diefenbach et al.).

Evidence from these paradigms suggests that response interference stems from the automatic, "stimulus-triggered" activation of action plans (DeSoto et al., 2001), as if distractors automatically activate the associated action plans. Accordingly, psychophysiological research shows that, in response interference, competition involves simultaneous activation of the brain areas associated with the target- and distractor-related responses (DeSoto et al., 2001; Mattler, 2005). Complementary evidence has been obtained from a more micro level of analysis: The activity of the neurons in the motor cortex that, in the aggregate, yield a population code corresponding to one vs. another action (e.g., moving the arm left or right; Georgopoulos et al., 1983; Bagrat and Georgopoulos, 1999). This research reveals that individual neurons can be found to fire, not only for the target-related action (i.e., the intended actions), but also for distractor-related actions (Cisek and Kalaska, 2005). Interestingly, although neurons actively code distractor-related action plans, this activation does not appear to influence one's conscious awareness about ongoing action:
One infers only that one's whole brain and musculature were concerned about executing the intended movement (see, in this issue, article by Filevich and Haggard). Research on automaticity (Puttemans et al., 2005) and on the consciously inaccessible neural mechanisms underlying action intentions (Libet, 2004) similarly reveal several sophisticated action-related processes that are unconscious.

Similarly, research on mirror neurons (Rizzolatti et al., 2008) has revealed that, when observing the actions of others, one is activating neural circuits that correspond to action planning, even though one may be motionless and utterly unconscious of these activations. This research also reveals that conscious percepts are intimately related to action control (James, 1890; Gibson, 1979; Llinás, 2002; Fuster, 2003). For example, Proffitt and colleagues (Proffitt et al., 2003; Witt et al., 2005) have shown that hills look steeper if one is carrying a heavy backpack or that objects appear closer when one is holding a tool that makes it easier to retrieve those objects (see also Firestone, 2013; Proffitt, 2013). For evidence regarding the role of functional knowledge in object identification, see Bub et al. (2003).

Additional evidence for unconsciously mediated actionrelated processing stems from the study of efference binding (Haggard et al., 2002a), which links perceptual processing to action/motor processing. This kind of stimulus-response binding allows one to learn to press a button when presented with a cue in a laboratory paradigm. Taylor and McCloskey $(1990,1996)$ demonstrated that, in a choice RT task, participants could select the correct motor response (one of two button presses) when confronted with subliminal stimuli (cf., Hallett, 2007). Unconscious efference binding also occurs in the case of reflexive responses to environmental stimuli, as in the pain withdrawal reflex. It is worth mentioning that, concerning unconscious integrations, the binding of perceptual information, known as afference binding (Morsella and Bargh, 2011) can also occur unconsciously, as is evident in intra- and inter-sensory illusions (e.g., the McGurk effect; McGurk and MacDonald, 1976). (The McGurk effect involves interactions between visual and auditory processes: An observer views a speaker mouthing "ga" while presented with the sound "ba." Surprisingly, the observer is unaware of any intersensory interaction, perceiving only "da.")

\section{CONSCIOUS ASPECTS OF ACTION CONTROL}

An appreciation of all that can transpire unconsciously during action control leads one to the following question. If so much in action control can be accomplished unconsciously, then what does consciousness contribute to action control? How and why is consciousness associated with some aspects of action control but not others?

When attempting to answer this question, one must consider that some aspects of action control do perturb consciousness strongly and reliably: (a) action-related mental imagery, (b) senses such as the sense of agency and sense of effort, and (c) actionrelated urges (e.g., arising under conditions of action conflict). We now discuss these under-explored conscious aspects of action control.

It has been demonstrated that the simultaneous activation of incompatible skeletomotor action plans, as when holding one's 
breath while underwater (where one is inclined to both inhale and not inhale) or suppressing a prepotent response in a response interference paradigm (see, in this issue, articles by Anguera et al., and by Lynn et al.), reliably influence consciousness (see quantitative review of evidence in Morsella et al., 2011). During such conscious conflicts (Morsella, 2005), a person experiences notable subjective "tuggings and pullings." Lewin (1935), Freud (1938), and Miller (1959) studied the nature of these intra-psychic conflicts. Often, in such conflicts, the expression of undesired action plans can be suppressed, but the subjectively experienced actionrelated inclinations cannot be (Bargh and Morsella, 2008). For instance, a person can suppress dropping a painfully hot dish of porcelain, but cannot suppress the subjective urges to drop the expensive dish (Morsella, 2005). In this way, inclinations can be behaviorally suppressed but most often cannot be mentally suppressed (Bargh and Morsella, 2008). These conscious conflicts stand in contrast to (a) conflicts involving smooth muscle (e.g., involving the pupillary reflex; cf., Morsella et al., 2009a), and (b) perceptual conflicts, which tend to be unconscious, as in the case of ventriloquism and McGurk effects (McGurk and MacDonald, 1976). This pattern of results suggests that the skeletal muscle system (an effector given the special appellation, "voluntary muscle") is intimately associated with conscious processing (see explanation in Morsella, 2005).

It should be noted that the interference paradigms mentioned above involve only punctate acts that are executed quickly (color naming and button pressing), placing minimal demands on working memory (WM). (See, in this issue, article by Anguera et al. and by Buchsbaum.) (WM has been defined as a temporary, capacity-limited storage system under attentional control that is used to intentionally hold, and manipulate, information in mind; Baddeley, 1986, 2007.) However, many of the conscious conflicts of everyday life-holding one's breath or gargling strong mouthwash for $30 \mathrm{sec}$ - are not fleeting, short-lived events, but events that unfold over time and make demands on WM, by requiring one to hold in mind an action goal (e.g., not expelling mouthwash before $30 \mathrm{sec}$; Hommel and Elsner, 2009). In everyday life, many goal-directed actions are also guided by representations that are not triggered by external stimuli (Miller et al., 1960; Neisser, 1967). (This also occurs in the phenomenon of prospective memory; see McDaniel and Einstein, 2007.) Sustaining the activation of such internally-generated representations is an effortful process, requiring that top-down activation strengthen one representation (e.g., the target or action goal) over another (e.g., task-irrelevant goals; Gazzaley et al., 2005). Thus, many everyday acts of action control are actually instances of WMbased action control, in which a person effortfully holds an action goal in mind while attempting to overcome goal-irrelevant interference.

Theoretical developments have forwarded the notion that WM is intimately related to both action control and consciousness (LeDoux, 2008). This is evident in the title and contents of a recent treatise, Working Memory, Thought, and Action (Baddeley, 2007). Indeed, perhaps no mental operation is as consistently coupled with consciousness as is WM (LeDoux, 2008). When trying to hold in mind action-related information, a person's consciousness is consumed by this goal (James, 1890). For instance, when holding a to-be-dialed telephone number in mind (or when gargling with mouthwash for $30 \mathrm{sec}$ ), action-related mental imagery occupies one's consciousness during the delayed action phase. Similarly, before making an important toast (or, more dramatically, making the toast in a foreign and unmastered language), a person has conscious imagery regarding the words to be uttered, much as when an actor rehearses lines for an upcoming scene (see, in this issue, article by Buchsbaum). In this way, before an act, the mind is occupied with perceptuallike representations of what that act is to be, as James (1890) stated: "In perfectly simple voluntary acts there is nothing else in the mind but the kinesthetic idea... of what the act is to be" (p. 771). Thus, voluntary action control often occupies both WM and consciousness. Common experience suggests that, during the delay before action production, action-related imagery enters one's consciousness. The imagery is isomorphic in some ways with the overt action goal, especially in the case of "subvocalization" (Morsella and Bargh, 2010), which involves "talking in one's head" (Levelt, 1989). In subvocalizing, auditory imagery is isomorphic in some way with what would be uttered (Levelt, 1989; Baddeley, 2007; Morsella et al., 2009b; Morsella and Bargh, 2010).

In addition to conscious conflicts, urges, and WM-related conscious imagery is the sense of agency, another conscious aspect of action control. The sense of agency is based on the perception of the lawful correspondence between action intentions and action outcomes (Haggard and Clark, 2003; Wegner, 2003; Hommel, 2009). For example, if one has the intention of flexing one's finger or of saying "hello" and then one's finger happens to flex or one hears oneself utter "hello," respectively, then one is likely to sense that one caused the action. This attribution is the outcome of conceptual processing (Synofzik et al., 2008a,b; Jeannerod, 2009) that takes into account information from various contextual factors (Wegner and Wheatley, 1999; Moore et al., 2009), including that of motor efference (Cole, 2007; Engbert et al., 2007; Tsakiris et al., 2007; Sato, 2009), proprioception (Balslev et al., 2007; Knoblich and Repp, 2009), and the perception of the real-world consequences of action intentions (Synofzik et al., 2009). This sense could be considered a form of metacognition (Dunlosky and Metcalfe, 2008).

By manipulating contextual factors, scores of experiments have demonstrated that subjects can be fooled into believing that they caused actions that were in fact caused by something else (Wegner, 2002). For example, when a participant's hand controls a computer-drawing device behind a screen such that the participant cannot see his or her hand in motion, the participant can be fooled into thinking (through false feedback on the computer display) that the hand intentionally moved in one direction when it actually moved in a slightly different direction (Fourneret and Jeannerod, 1998). With such techniques, participants in another study were tricked into believing that they could control the movements of stimuli on a computer screen through a phony brain-computer interface (Lynn et al., 2010). When intentions and outcomes mismatch, people are less likely to perceive actions as originating from the self (Wegner, 2002).

Most of these studies examine how agency is influenced by intention-outcome mismatches or illusory intention-outcome 
matches. There are several "comparator models" explaining how intention-outcome mismatches are detected and influence various levels of agency. Importantly, different theorists link the sense of agency and urges to different phases of the process (cf., Haggard, 2005, 2008; Berti and Pia, 2006; David et al., 2008). Complementing research on the sense of agency are investigations on the sense of effort during action control (Sherrington, 1900, 1906; Gandevia, 1982) and the sense of body ownership (e.g., in the rubber hand illusion; Botvinick and Cohen, 1998) and of actions generated toward the body (e.g., tickling-related illusions; Blakemore et al., 2000). Additionally, states described as flow (Csikszentmihalyi, 1990) and effortless attention (Bruya, 2010) have been associated with forms of action control. Moreover, theorists of the Würzburg School (e.g., Külpe, Ach, and Marbe) have discussed several, action-related conscious attitudes, including doubt, hesitation, certainty, and will to enact a certain change in the world.

We will now survey some less intuitive properties of actionrelated conscious processing. First, there is a peculiar property of voluntary action that appears to not be shared by other (e.g., involuntary) forms of action. For reasons unknown, in intentional binding, the perceived elapsed time between a voluntary action and its consequence is shorter than the actual time span (Haggard et al., 2002b), as if the two events were temporally attracted to each other. Thus, when striking a bell voluntarily, the experiences of striking the bell and of hearing the gong of the bell are perceived to occur more closely together in time than they actually did.

Another property of action-related consciousness arises in the paradigm of binocular rivalry (see Logothetis article). In this paradigm (see review in Alais and Blake, 2005), participants are first trained to respond in certain ways when presented with visual stimuli (e.g., to button-press when presented with the image of a house). After training, a different stimulus is presented to each eye (e.g., an image of a house to one eye and of a tree to the other). Surprisingly, the participant does not consciously perceive both objects (e.g., a tree overlapping a house), but responds as if perceiving only one object at a time (e.g., a house followed by a tree). During rivalry, the conscious percept is said to be "dominant," and the unconscious percept is said to be "suppressed."

The mind's process of switching dominance between each eye can be manipulated in interesting ways. Maruya et al. (2007) demonstrated that voluntary action can influence which percept enters awareness: The object that moved in synchrony with participants' voluntary movements of a computer mouse was dominant for a longer period of time and suppressed for a shorter period of time. Rivalry stimuli consisted of a radial grating (resembling the pattern on a dart board) and a rotating sphere that was transparent and defined solely by dots. Prior to test, participants learned to move a computer mouse in a continuous left-to-right motion. Participants later performed this motion under conditions of rivalry. Maruya et al. (2007) concluded, "conflict between two incompatible visual stimuli tends to be resolved in favor of a stimulus that is under motor control of the observer viewing that stimulus" (p. 1096), revealing "a strong link between action and perception" (p. 1090). This finding is consistent with that of Wohlschläger (2000), who reported that, while perceiving a perceptually bistable apparent rotation of an object, participants were more likely to perceive the object as rotating in the direction in which they happened to be rotating a knob (Repp and Knoblich, 2007), a case of perceptual resonance (Wohlschläger, 2000; Schütz-Bosbach and Prinz, 2007). Consistent with the finding by Maruya et al. (2007), Doesburg et al. (2009) found in a psychophysiological study that it is only during the dominant percept that perceptual processing associated with the percept is coupled with motor-related processes in frontal cortex. (Additional evidence stems from a recent study showing that entry of any kind may require a top-down signal from frontal cortex; Boly et al., 2011; Panagiotaropoulos et al., 2012.)

Perceptual resonance, and the voluntary control of action, can be explained by ideomotor theory (Lotze, 1852; Harleß, 1861; James, 1890; Greenwald, 1970; Hommel et al., 2001; Hommel, 2009; Hommel and Elsner, 2009). When popularizing this theory, William James (1890) proposed that the mere thoughts of actions produce impulses that, if not curbed or controlled by thoughts of incompatible actions, result in the performance of the imagined actions (see Marien et al., this issue). From this view, activating the perceptual effects of an action leads to the corresponding action-effortlessly and without awareness of the motor programs involved (Gray, 1995; Kunde, 2004). The representations guiding action production tend to be perceptual-like images of action outcomes (Hommel, 2009), which are based on memories of prior action outcomes (see, in this issue, Marien et al. for role of reward in ideomotor learning). Consistent with ideomotor theory, during conflicts such as those of the Stroop task, it is perceptual-like representations that are activated to guide action (Enger and Hirsch, 2005).

Because action/motor processes are largely unconscious (Grossberg, 1999; Goodale and Milner, 2004; Gray, 2004), the entry into consciousness of content is influenced most by perceptual-based (and not action-based) events and processes (e.g., priming by perceptual representations; Müller, 1843; James, 1890; Gray, 2004; Morsella and Bargh, 2010). [See brain stimulation evidence in Desmurget et al. (2009).] Hence, few conscious contents should arise from what can be construed as "pure" action-related processes (should there be such a thing; cf., Hommel, 2009). Thus, entry from action in Maruya et al. (2007) might be the result of the more "perceptual" aspects of action production, such as perceptual-like action effect representations (or "Effektbild"; Harleß, 1861) or corollary discharges from action plans (Gray, 2004). From this standpoint, though perception and action are intimately related and may even share the same representational format, as in "common code" models of perception-and-action (Hommel, 2009), when it comes to phenomenology, consciousness is most influenced by what has traditionally been regarded as the perceptual end of the perception-action cycle (Neisser, 1976; Gray, 1995). Accordingly, research by Wohlschläger (2000) and by ideomotor theorists (e.g., Hommel, 2009) suggests that action-based effects on awareness such as perceptual resonance require, not only perturbation of the sensorium, but dimensional overlap (e.g., shared spatial dimensions) between actions and percepts (cf., Knuf et al., 2001; Schütz-Bosbach and Prinz, 2007). 
As noted, some ideomotor models propose that perceptual action effects and action codes share the same representational format, hence the description of some ideomotor accounts as common code theories of perception-and-action (Hommel, 2009). Such common code perspectives resemble mirror neuron approaches (Rizzolatti et al., 2008) and motor theories of speech perception (Liberman and Mattingly, 1985). (For a treatment of action simulation, see, in this issue, Springer et al.) Similarly, speaking about the interconnection between perception and action, Sperry (1952) proposed that the phenomenal percept (e.g., the shape of a banana) is more isomorphic with its related action plans (grabbing or drawing the banana) than with its sensory input (the proximal stimulus on the retina). [For contemporary treatments regarding how action influences the nature of conscious percepts, see Gray (1995), Hochberg (1998), O’Regan and Noë (2001), and Humphreys (2013).]

With great influence, Gibson (1979) too proposed an "ecological theory" of perception in which perception is intimately related to action, but, unlike ideomotor theory and common code approaches, Gibson's approach is strictly non-representational in that all the information necessary for action was provided and contained by the environment. For a treatment regarding the difference between ecological and representational ("cognitive") theories of action, see Hommel et al. (2001). See Sheerer (1984) and Markman (1999) for reviews of the shortcomings of approaches in which the nature of percepts or, more generally, representations, is constituted in part by motor processing, as in "peripheralist," "motor," "embodied," "efferent," and "reafferent" theories of thought (e.g., Münsterberg, 1891; Watson, 1924; Washburn, 1928; Held and Rekosh, 1963; McGuigan, 1966; Festinger et al., 1967; Hebb, 1968; see discussion of embodied approaches in Deifenbach et al., this issue; see relevant article by Jordan, in this issue).

\section{CONCLUSION TO THE INTRODUCTION OF THE SPECIAL ISSUE ON CONSCIOUSNESS AND ACTION CONTROL}

Our survey and the following articles reveal that one of the primary reasons to study consciousness by way of action control

\section{REFERENCES}

Agnew, C. R., Carlston, D. E., Graziano, W. G., and Kelly, J. R. (2009). Then a Miracle Occurs: Focusing on Behavior in Social Psychological Theory and Research. New York, NY: Oxford University Press. doi: 10.1093/acprof:oso/9780195377798. 001.0001

Alais, D., and Blake, R. (2005). Binocular Rivalry. Cambridge, MA: The MIT Press.

Allport, D. A. (1989). "Visual attention," in Foundations of Cognitive Science, Vol. 2, ed M. I. Posner (Cambridge, MA: MIT Press), 631-682.

Arkin, R. C. (1998). Behavior-Based Robotics. Cambridge, MA: The MIT Press.

Aru, J., Bachmann, T., Singer, W., and Melloni, L. (2012).

is that the contrast between conscious and unconscious processes is easy to appreciate from an action-based standpoint. It is important to consider that, though it is far from trivial to demonstrate unconscious perceptual processing-a controversial phenomenon whose study often requires neuroimaging and sophisticated techniques (e.g., perceptual priming)_even the most cursory examination of action phenomena reveals that, in the nervous system, there is the distinction of processes that are consciously mediated (e.g., voluntary action) and unconsciously mediated (e.g., reflexes, peristalsis, and aspects of motor control). Stumbling upon this contrast between conscious and unconscious processes is not only uncontroversial in the study of action but is inevitable. In addition, it is more experimentally tractable to study the relationship between action and consciousness than that between attention and consciousness (the traditional approach; cf., Baars, 1997), because in the former there is less likelihood of conflating conscious and attentional processes (cf., Hamker, 2003), a recurring problem in consciousness research (Baars, 1997; Maruya et al., 2007). Last, what Sperry noted in 1952 about action is still true: The outputs of a system reveal more about the inner workings of the system than do the inputs to the system. As the cardinal "output" of the nervous system (Morsella and Bargh, 2010), action thus provides the investigator with a unique portal to illuminate the most elusive of central processes, consciousness.

\section{ACKNOWLEDGMENTS}

We would like to thank Professor Lorenza Colzato, Professor Bernhard Hommel, and the editorial staff at Frontiers in Cognition for giving us the honor of serving as editors of this special issue and for assisting us throughout the entire editorial process. We are also indebted to the contributors of the special volume. They have shared with us and the readership of Frontiers in Cognition theoretical and empirical advancements that will be studied for years to come. Ezequiel Morsella acknowledges the support provided by the Center for Human Culture and Behavior at San Francisco State University.

6, 47-52. doi: 10.1016/S1364-6613 (00)01819-2

Distilling the neural correlates of consciousness. Neurosci. Biobehav. Rev. 36, 737-746. doi: 10.1016/j.neubiorev.2011.12.003

Baars, B. J. (1988). A Cognitive Theory of Consciousness. Cambridge, UK: Cambridge University Press.

Baars, B. J. (1997). Some essential differences between consciousness and attention, perception, and working memory. Conscious. Cogn. 6, 363-371. doi: 10.1006/ccog.1997. 0307

Baars, B. J. (1998). The function of consciousness: reply. Trends Neurosci. 21, 201. doi: 10.1016/S0166-2236(98)01252-1

Baars, B. J. (2002). The conscious access hypothesis: origins and recent evidence. Trends Cogn. Sci.
Baars, B. J. (2005). Global workspace theory of consciousness: toward a cognitive neuroscience of human experience. Prog. Brain Res. 150, 45-53. doi: 10.1016/S0079-6123 (05)50004-9

Baars, B. J. (2013). Global workspace dynamics: cortical "binding and propagation" enables conscious contents. Front. Psychol. 4:200. doi: 10.3389/fpsyg.2013.00200

Baddeley, A. D. (1986). Working Memory. Oxford, England: Oxford University Press.

Baddeley, A. D. (2007). Working Memory, Thought and Action. Oxford: Oxford University Press. doi: $\quad 10.1093 /$ acprof:oso/9780198 528012.001.0001
Bagrat, A., and Georgopoulos, A. P. (1999). Cortical populations and behavior: Hebb's thread. Can. J. Exp. Psychol. 53, 21-34. doi: 10.1037/h0087297

Balslev, D., Cole, J., and Miall, R. C. (2007). Proprioception contributes to the sense of agency during visual observation of hand movements: evidence from temporal judgments of action. J. Cogn. Neurosci. 19, 1535-1541. doi: 10.1162/jocn.2007. 19.9.1535

Bargh, J. A., and Chartrand, T. L. (2000). "A practical guide to priming and automaticity research," in Handbook of Research Methods in Social Psychology, eds H. Reis and C. Judd, (New York, NY: Cambridge University Press), 253-285. 
Bargh, J. A., and Morsella, E. (2008). The unconscious mind. Perspect. Psychol. Sci. 3, 73-79. doi: 10.1111/j.1745-6916.2008.00064.x

Berti, A., and Pia, L. (2006). Understanding motor awareness through normal and pathological behavior. Curr. Dir. Psychol. Sci. 15, 245-250. doi: 10.1111/j.1467-8721. 2006.00445.x

Blakemore, S. J., Wolpert, D., and Frith, C. (2000). Why can't you tickle yourself? Neuroreport 3, R11-R16. doi: 10.1097/00001756-20000803000002

Blanken, G., Wallesch, C.-W., and Papagno, C. (1990). Dissociations of language functions in aphasics with speech automatisms (recurring utterances). Cortex 26, 41-63. doi: 10.1016/S0010-9452 (13)80074-3

Bleuler, E. (1924). Textbook of Psychiatry. Transl. A. A. Brill. New York, NY: The Macmillan Company.

Boly, M., Garrido, M. I., Gosseries, O., Bruno, M.-A., Boveroux, P., Schnakers, C., Massimini, M., et al. (2011). Preserved feedforward but impaired top-down processes in the vegetative state. Science 332, 858-862. doi: 10.1126/science.120 2043

Botvinick, M., and Cohen, J. (1998). Rubber hands 'feel' touch that eyes see. Nature 391, 756. doi: $10.1038 / 35784$

Bruya, B. (2010). Effortless Attention: A New Perspective in the Cognitive Science of Attention and Action. Cambridge, MA: The MIT Press.

Bub, D. N., Masson, M. E. J., and Bukach, C. M. (2003). Gesturing and naming: the use of functional knowledge in object identification. Psychol. Sci. 14, 467-472. doi: 10.1111/1467-9280.02455

Cisek, P., and Kalaska, J. F. (2005). Neural correlates of reaching decisions in dorsal premotor cortex: specification of multiple direction choices and final selection of action. Neuron 45, 801-814. doi: 10.1016/j.neuron. 2005.01.027

Clark, A. (2002). Is seeing all it seems? Action, reason and the grand illusion. J. Conscious. Stud. 9, 181-202.

Cohen, J. D., Dunbar, K., and McClelland, J. L. (1990). On the control of automatic processes: a parallel distributed processing account of the Stroop effect. Psychol. Rev. 97, 332-361. doi: 10.1037/0033-295X.97.3.332

Cole, J. (2007). The phenomenology of agency and intention in the face of paralysis and insentience.
Phenomenol. Cogn. Sci. 6, 309-325. doi: 10.1007/s11097-007-9051-5

Crick, F. (1995). The Astonishing Hypothesis: The Scientific Search for the Soul. New York, NY: Touchstone.

Crick, F., and Koch, C. (1995). Are we aware of neural activity in primary visual cortex? Nature 375, 121-123. doi: $10.1038 / 375121 \mathrm{a} 0$

Crick, F., and Koch, C. (2003). A framework for consciousness. Nat. Neurosci. 6, 1-8. doi: 10.1038/nn0203-119

Csikszentmihalyi, M. (1990). Flow: The Psychology of Optimal Experience. New York, NY: Harper Perennial Modern Classics.

Curtis, C. E., and D'Esposito, M. (2009). "The inhibition of unwanted actions," in Oxford Handbook of Human Action, eds E. Morsella, J. A. Bargh, and P. M. Gollwitzer, (New York, NY: Oxford University Press), 72-97.

Damasio, A. R. (1989). Time-locked multiregional retroactivation: a systems-level proposal for the neural substrates of recall and recognition. Cognition 33, 25-62. doi: 10.1016/0010-0277 (89) $90005-\mathrm{X}$

Damasio, A. R. (2010). Self Comes to Mind: Constructing the Conscious Brain. New York, NY: Pantheon.

David, N., Newen, A., and Vogeley, K. (2008). The "sense of agency" and its underlying cognitive and neural mechanisms. Conscious. Cogn. 17, 523-534. doi: 10.1016/j.concog.2008.03.004

de Waal, F. B. M. (2002). Evolutionary psychology: the wheat and the chaff. Curr. Dir. Psychol. Sci. 11, 187-191. doi: 10.1111/1467-8721.00197

Dehaene, S., and Naccache, L. (2001). Towards a cognitive neuroscience of consciousness: basic evidence and a workspace framework. Cognition 79, 1-37. doi: 10.1016/S0010-0277(00)00123-2

Del Cul, A., Baillet, S., and Dehaene, S. (2007). Brain dynamics underlying the nonlinear threshold for access to consciousness. PLoS Biol. 5:e260. doi: 10.1371/journal.pbio.0050260

Desmurget, M., Reilly, K. T., Richard, N., Szathmari, A., Mottolese, C. and Sirigu, A. (2009). Movement intention after parietal cortex stimulation in humans. Science 324 , 811-813.

DeSoto, M. C., Fabiani, M., Geary, D. C., and Gratton, G. (2001) When in doubt, do it both ways: brain evidence of the simultaneous activation of conflicting responses in a spatial Stroop task. J. Cogn. Neurosci. 13, 523-536. doi: 10.1162/08989290152001934
Di Lollo, V., Enns, J. T., and Rensink, R. A. (2000). Competition for consciousness among visual events: the psychophysics of reentrant visual pathways. J. Exp. Psychol. Gen. 129, 481-507. doi: 10.1037/0096-3445. 129.4.481

Doesburg, S. M., Green, J. L., McDonald, J. J., and Ward, L. M. (2009). Rhythms of consciousness: binocular rivalry reveals large-scale oscillatory network dynamics mediating visual perception. PLoS ONE 4:e6142. doi: 10.1371/journal.pone.0006142

Dunlosky, J., and Metcalfe, J. (2008). Metacognition: a Textbook for Cognitive, Educational, Life Span, and Applied Psychology. Thousand Oaks, CA: Sage Publishers.

Edelman, G. M., and Tononi, G. (2000). A Universe of Consciousness: How Matter Becomes Imagination, 1st Edn. New York, NY: Basic Books.

Ellis, R. (2009). "Interactions between action and visual objects," in Oxford Handbook of Human Action, eds E. Morsella, J. A. Bargh, and P. M Gollwitzer, (New York, NY: Oxford University Press), 214-224.

Enatsu, R., Hantus, S., GonzalezMartinez, J., and So, N. (2011) Ictal singing due to left frontal lobe epilepsy: a case report and review of the literature. Epilepsy Behav. 22, 404-406. doi: 10.1016/j.yebeh.2011. 07.019

Engbert, K., Wohlschläger, A., and Haggard, P. (2007). Who is causing what? The sense of agency is relational and efferent triggered. Cognition 107, 693-704. doi: 10.1016/j.cognition.2007.07.021

Enger, T., and Hirsch, J. (2005). Cognitive control mechanisms resolve conflict through cortical amplification of task-relevant information. Nat. Neurosci. 8 , 1784-1790. doi: 10.1038/nn1594

Eriksen, B. A., and Eriksen, C. W (1974). Effects of noise letters upon the identification of a target letter in a nonsearch task. Percept. Psychophys. 16, 143-149. doi: 10.3758/BF03203267

Eriksen, C. W., and Schultz, D. W. (1979). Information processing in visual search: a continuous flow conception and experimental results. Percept. Psychophys. 25, 249-263. doi: 10.3758/BF03198804

Fecteau, J. H., Chua, R., Franks, I., and Enns, J. T. (2001). Visual awareness and the online modification of action. Can. J. Exp. Psychol. 55, 104-110. doi: 10.1037/h0087357

Festinger, L., Ono, H., Burnham, C. A., and Bamber, D. (1967). Efference and the conscious experience of perception. J. Exp. Psychol. Monogr. 74, 1-36. doi: 10.1037/h0024766

Firestone, C. (2013). How 'paternalistic' is spatial perception? Why wearing a heavy backpack doesn't-and couldn't-make hills look steeper. Perspect. Psychol. Sci. 8, 455-473. doi: 10.1177/1745691613489835

Fischer, R., Plessow, F., and Kiesel, A. (2013). The effects of alerting signals in masked priming. Front. Psychol. 4:448. doi: 10.3389/fpsyg. 2013.00448

Fourneret, P., and Jeannerod, M. (1998). Limited conscious monitoring of motor performance in normal subjects. Neuropsychologia 36, 1133-1140. doi: 10.1016/S00283932(98)00006-2

Freeman, W. J. (1991). The physiology of perception. Sci. Am. 264, 78-85. doi: 10.1038/scientific american0291-78

Freud, S. (1938). The Basic Writings of Sigmund Freud, eds A. Transl and A. Brill, (New York, NY: Modern Library).

Frith, C. D., Blakemore, S. J., and Wolpert, D. M. (2000). Abnormalities in the awareness and control of action. Philos. Trans. R. Soc. Lond. 355, 1771-1788. doi: 10.1098/rstb.2000.0734

Fuster, J. M. (2003). Cortex and Mind: Unifying Cognition. New York, NY: Oxford University Press.

Gandevia, S. C. (1982). The perception of motor commands or effort during muscular paralysis. Brain 105, 151-159. doi: 10.1093/brain/105.1.151

Gazzaley, A., Cooney, J. W., Rissman, J., and D'Esposito, M. (2005). Topdown suppression deficit underlies working memory impairment in normal aging. Nat. Neurosci. 8 1298-1300. doi: 10.1038/nn1543

Gazzaley, A., and D’Esposito, M. (2007). "Unifying prefrontal cortex function: executive control, neural networks and top-down modulation," in The Human Frontal Lobes: Functions and Disorders, eds B. Miller and J. Cummings (New York, NY: Guilford Press), 187-206.

Georgopoulos, A. P., Caminiti, R., Kalaska, J. F., and Massey, J. T. (1983). Spatial coding of movement: a hypothesis concerning the coding of movement direction by motor cortical populations. Exp. Brain Res. Suppl. 7, 327-336. doi: 10.1007/978-3-642-68915-4_34

Gibson, J. J. (1979). The Ecological Approach to Visual Perception. Boston, MA: Houghton-Mifflin.

Godwin, C. A., Gazzaley, A., and Morsella, E. (2013). "Homing in on the brain mechanisms linked 
to consciousness: buffer of the perception-and-action interface," in The Unity of Mind, Brain and World: Current Perspectives on a Science of Consciousness, eds A. Pereira and D. Lehmann's (Cambridge, UK: Cambridge University Press), 43-76.

Goodale, M., and Milner, D. (2004). Sight Unseen: An Exploration of Conscious and Unconscious Vision. New York, NY: Oxford University Press.

Goodhew, S. C., Dux, P. E., Lipp, O. V., and Visser, T. A. W. (2012). Understanding recovery from object substitution masking. Cognition 122, 405-415. doi: 10.1016/j. cognition.2011.11.010

Gould, S. J. (1977). Ever since Darwin: Reflections in Natural History. New York, NY: Norton.

Gray, J. A. (1995). The contents of consciousness: a neuropsychological conjecture. Behav. Brain Sci. 18, 659-676. doi: 10.1017/S0140525X00040395

Gray, J. A. (2004). Consciousness: Creeping up on the Hard Problem. New York, NY: Oxford University Press.

Graziano, M. S. A. (2001). Awareness of space. Nature 411, 903-904. doi: $10.1038 / 35082182$

Greenwald, A. G. (1970). Sensory feedback mechanisms in performance control: with special reference to the ideomotor mechanism. Psychol. Rev. 77, 73-99. doi: 10.1037/h0028689

Greenwald, A. G., McGhee, D. E., and Schwartz, J. L. K. (1998). Measuring individual differences in implicit cognition: the implicit association test. J. Pers. Soc. Psychol. 74, 1464-1480. doi: 10.1037/00223514.74.6.1464

Grossberg, S. (1999). The link between brain learning, attention, and consciousness. Conscious. Cogn. 8, 1-44. doi: 10.1006/ccog.1998.0372

Haggard, P. (2005). Conscious intention and motor cognition. Trends Cogn. Sci. 9, 290-295. doi: 10.1016/j.tics.2005.04.012

Haggard, P. (2008). Human volition: towards a neuroscience of will. Nat. Neurosci. Rev. 9, 934-946. doi: 10.1038/nrn2497

Haggard, P., Aschersleben, G., Gehrke, J., and Prinz, W. (2002a). "Action, binding and awareness," in Common Mechanisms in Perception and Action: Attention and Performance, Vol. XIX, eds W. Prinz and B. Hommel (Oxford, UK: Oxford University Press), 266-285.

Haggard, P., Clark, S., and Kalogeras, J. (2002b). Voluntary action and conscious awareness. Nat. Neurosci. 5, 382-385. doi: 10.1038/nn827

Haggard, P., and Clark, S. (2003). Intentional action: conscious experience and neural prediction. Conscious. Cogn. 12, 695-707. doi: 10.1016/S1053-8100(03)00052-7

Hallett, P. E. (1978). Primary and secondary saccades to goals defined by instructions. Vis. Res. 18, 1279-1296. doi: 10.1016/0042-6989 (78) $90218-3$

Hallett, M. (2007). Volitional control of movement: the physiology of free will. Clin. Neurophysiol. 117, 1179-1192. doi: 10.1016/j.clinph. 2007.03.019

Hamker, F. H. (2003). The reentry hypothesis: linking eye movements to visual perception. J. Vis. 11, 808-816.

Harleß, E. (1861). Der apparat des willens [The apparatus of the will]. Zeitshrift für Philosophie und philosophische Kritik 38, 499-507.

Heath, M., Neely, K. A., Yakimishyn, J., and Binsted, G. (2008). Visuomotor memory is independent of conscious awareness of target features. Exp. Brain Res. 188, 517-527. doi: 10.1007/s00221-008-1385-x

Hebb, D. O. (1968). Concerning imagery. Psychol. Rev. 75, 466-477. doi: 10.1037/h0026771

Heilman, K. M., Watson, R. T., and Valenstein, E. (2003). "Neglect: clinical and anatomic issues," in Behavioral Neurology and Neuropsychology, 2nd Edn., eds T. E. Feinberg and M J. Farah (New York, NY: The McGraw-Hill Companies), 303-311.

Held, R., and Rekosh, J. (1963). Motor-sensory feedback and the geometry of visual space. Science 141, 722-723. doi: 10.1126/science.141.3582.722

Herwig, A., Beisert, M., and Prinz, W. (2013). "Action science emerging: introduction and leitmotifs," in Action Science, eds W. Prinz, M. Beisert, and A. Herwig (Cambridge, MA: The MIT Press), 1-33.

Hochberg, J. (1998). "Gestalt theory and its legacy: organization in eye and brain, in attention and mental representation," in Perception and Cognition at Century's End, Handbook of Perception and Cognition, 2nd Edn., ed J. Hochberg (San Diego, CA: Academic Press), 253-306.

Hommel, B. (2009). Action control according to TEC (theory of event coding). Psychol. Res. 73, 512-526. doi: 10.1007/s00426-009-0234-2

Hommel, B., and Elsner, B. (2009). "Acquisition, representation, and control of action," in Oxford
Handbook of Human Action, eds E. Morsella, J. A. Bargh, and P. M. Gollwitzer (New York, NY: Oxford University Press), 371-398.

Hommel, B., Müsseler, J., Aschersleben, G., and Prinz, W. (2001). The theory of event coding: a framework for perception and action planning Behav. Brain Sci. 24, 849-937. doi: 10.1017/S0140525X01000103

Hubbard, J., Rigby, T., Godwin, C. A., Gazzaley, A., and Morsella, E. (2013). Representations in working memory yield interference effects found with externally-triggered representations. Acta Psychol. 142, 127-135. doi: 10.1016/j.actpsy.2012. 11.005

Humphreys, G. W. (2013). "Beyond serial stages for attentional selection: the critical role of action," in Action Science, eds W. Prinz, M. Beisert, and A. Herwig (Cambridge, MA: The MIT Press), 229-251.

James, W. (1890). The Principles of Psychology. New York, NY: Dover. doi: 10.1037/11059-000

Jeannerod, M. (2006). Motor Cognition: What Action Tells the Self. New York, NY: Oxford University Press. doi: 10.1093/acprof:oso/978019 8569657.001.000

Jeannerod, M. (2009). The sense of agency and its disturbances in schizophrenia: a reappraisal. Exp. Brain Res. 196, 527-532. doi: 10.1007/s00221-008-1533-3

Johnson, H., and Haggard, P. (2005) Motor awareness without perceptual awareness. Neuropsychologia 43, 227-237. doi: 10.1016/ j.neuropsychologia.2004.11.009

Johnson, M. R., and Johnson, M. K. (2009). "Toward characterizing the neural correlates of component processes of cognition," in Neuroimaging of human memory: Linking cognitive processes to neural systems, eds F. Roesler, C. Ranganath, B. Roeder, and R. H. Kluwe (New York, NY: Oxford University Press). 169-194. doi: $\quad 10.1093 /$ acprof:oso/9780199 217298.003.0010

Kahneman, D. (1973). Attention and Effort. Englewood Cliffs, NJ: Prentice Hall.

Kececi, H., Degirmenci, Y., and Gumus, H. (2013). Two foreign language automatisms in complex partial seizures. Epilepsy Behav. Case Rep. 1, 7-9. doi: 10.1016/j.ebcr. 2012.10.005

Kinsbourne, M. (1996). "What qualifies a representation for a role in consciousness?" in Scientific Approaches to Consciousness, eds J. D. Cohen and J. W. Schooler (Hillsdale, NJ: Erlbaum), 335-355.
Knoblich, G., and Repp, B. H. (2009). Inferring agency from sound. Cognition 111, 248-262. doi: 10.1016/j.cognition.2009.02.007

Knuf, L., Aschersleben, G., and Prinz, W. (2001). An analysis of ideomotor action. J. Exp. Psychol. Gen. 130, 779-798. doi: 10.1037/0096 3445.130 .4 .779

Koch, C. (2004). The Quest For Consciousness: A Neurobiological Approach. Colorado: Roberts and Company.

Koch, C. (2012). Consciousness: Confessions of a Romantic Reductionist. Cambridge, MA: MIT Press.

Kriegel, U. (2007). A cross-order integration hypothesis for the neural correlate of consciousness. Conscious. Cogn. 16, 897-912. doi: 10.1016/j.concog.2007.02.001

Kunde, W. (2001). Response-effect compatibility in manual choice reaction tasks. J. Exp. Psychol. Hum. Percept. Perform. 27, 387-394. doi: 10.1037/0096-1523.27.2.387

Kunde, W. (2004). Response priming by supraliminal and subliminal action effects. Psychol. Res. 68, 91-96. doi: 10.1007/s00426-0030147-4

Lappin, J. S., and Eriksen, C. W. (1966). Use of a delayed signal to stop a visual reaction time response. J. Exp. Psychol. 72, 805-811. doi: 10.1037/h0021266

Lau, H. C., Rogers, R. D., Haggard, P., and Passingham, R. E. (2004). Attention to intention. Science 303, 1208-1210. doi: $10.1126 /$ science. 1090973

Laureys, S. (2005). The neural correlate of (un)awareness: lessons from the vegetative state. Trends Cogn. Sci. 12, 556-559. doi: 10.1016/j.tics.2005.10.010

LeDoux, J. E. (2008). "Emotional colouration of consciousness: how feelings come about," in Frontiers of consciousness, eds L. W. Weiskrantz and M. Davies (Oxford, UK Oxford University Press), 69-130. doi: $\quad 10.1093 /$ acprof:oso/978019 9233151.003 .0003

Levelt, W. J. M. (1989). Speaking: From Intention to Articulation. Cambridge, MA: The MIT Press.

Lewin, K. (1935). A Dynamic Theory of Personality. New York, NY: McGraw-Hill.

Lhermitte, F. (1983). "Utilization behaviour" and its relation to lesions of the frontal lobe. Brain 106, 137-255. doi: 10.1093/brain/ 106.2.237

Liberman, A. M., and Mattingly, I. G. (1985). The motor theory of speech perception 
revised. Cognition 21, 1-36. doi: 10.1016/0010-0277(85)90021-6

Libet, B. (2004). Mind Time: The Temporal Factor in Consciousness. Cambridge, MA: Harvard University Press

Lieberman, M. D. (2007). "The Xand C-systems: the neural basis of automatic and controlled social cognition," in Fundamentals of Social Neuroscience, eds E. Harmon-Jones and P. Winkielman (New York, NY: Guilford), 290-315.

Liu, G., Chua, R., and Enns, J. T. (2008). Attention for perception and action: task interference for action planning, but not for online control. Exp. Brain Res. 185, 709-717. doi: 10.1007/s00221-007-1196-5

Llinás, R. R. (2002). I of the Vortex: From Neurons to Self. Cambridge, MA: MIT Press.

Llinás, R. R., and Ribary, U. (2001). Consciousness and the brain: the thalamocortical dialogue in health and disease. Ann N.Y. Acad. Sci. 929, 166-175. doi: 10.1111/j.17496632.2001.tb05715.x

Logan, G. D., and Gordon, R. D. (2001). Executive control of visual attention in dual-task situations. Psychol. Rev. 108, 393-494. doi: 10.1037/0033295X.108.2.393

Logothetis, N. K., and Schall, J. D. (1989). Neuronal correlates of subjective visual perception. Science 245, 761-762. doi: 10.1126/science. 2772635

Lorenz, K. (1963). On Aggression. New York, NY: Harcourt, Brace, and World.

Lotze, R. H. (1852). Medizinische Psychologie oder Physiologie der Seele. Leipzig: Weidmann'sche Buchhandlung.

Lynn, M. T., Berger, C. C., Riddle, T. A., and Morsella, E. (2010). Mind control? creating illusory intentions through a phony braincomputer interface. Conscious. Cogn. 19, 1007-1012. doi: 10.1016/j.concog.2010.05.007

MacLeod, C. M. (1991). Half a century of research on the Stroop effect: an integrative review. Psychol. Bull. 109, 163-203. doi: 10.1037/00332909.109.2.163

MacLeod, C. M., and Dunbar, K. (1988). Training and Stroop-like interference: evidence for a continuum of automaticity. J. Exp. Psychol. Learn. Mem. Cogn. 14, 126-135. doi: 10.1037/0278-7393.14.1.126

MacLeod, C. M., and MacDonald, P. A. (2000). Interdimensional interference in the Stroop effect: uncovering the cognitive and neural anatomy of attention.
Trends Cogn. Sci. 4, 383-391. doi: 10.1016/S1364-6613(00)01530-8

Marchetti, C., and Della Sala, S. (1998). Disentangling the alien and anarchic hand. Cogn. Neuropsychiatry 3, 191-207. doi: 10.1080/13546809839 6143

Marcus, G. (2008). Kluge: The Haphazard Construction of the Mind. Boston, MA: Houghton Mifflin Company.

Markman, A. B. (1999). Knowledge Representation. Hillsdales, NJ: Lawrence Erlbaum Associates, Publishers.

Maruya, K., Yang, E., and Blake, R. (2007). Voluntary action influences visual competition. Psychol. Sci. 18, 1090-1098. doi: 10.1111/j.14679280.2007.02030.x

Mattler, U. (2005). Flanker effects on motor output and the late-level response activation hypothesis. Q. J. Exp. Psychol. 58A, 577-601.

McClelland, J. L. (1979). On the timerelations of mental processes: an examination of systems of processes in cascade. Psychol. Rev. 86, 287-330. doi: 10.1037/0033295X.86.4.287

McDaniel, M. A., and Einstein, G. O. (2007). Prospective Memory: An Overview and Synthesis of an Emerging Field. Thousand Oaks, CS: Sage Publishers.

McGuigan, F. J. (1966). Thinking. Studies of Covert Language Processes. New York, NY: Appleton-Century-Crofts.

McGurk, H., and MacDonald, J. (1976). Hearing lips and seeing voices. Nature 264, 746-748. doi: $10.1038 / 264746 \mathrm{a} 0$

Merker, B. (2007). Consciousness without a cerebral cortex: a challenge for neuroscience and medicine. Behav. Brain Sci. 30, 63-134. doi: 10.1017/S0140525X 07000891

Merker, B. (2013). The efference cascade, consciousness, and its self: naturalizing the first person pivot of action control. Front. Psychol. 4:501. doi: 10.3389/fpsyg. 2013.00501

Miall, R. C. (2003). Connecting mirror neuron and forward models. Neuroreport 14, 1-3. doi: 10.1097/ 00001756-200312020-00001

Miller, G. A., Galanter, E., and Pribram, K. H. (1960). Plans and the Structure of Behavior. New York, NY: Holt. doi: 10.1037/10039-000

Miller, N. E. (1959). "Liberalization of basic S-R concepts: extensions to conflict behavior, motivation, and social learning," in Psychology: A Study of Science, Vol. 2, ed S.
Koch (New York, NY: McGrawHill), 196-292.

Milner, A. D., and Goodale, M. (1995) The Visual Brain in Action. New York, NY: Oxford University Press.

Milner, B. (1966). "Amnesia following operation on the temporal lobes," in Amnesia, eds C. W. M. Whitty and O. L. Zangwill (London: Butterworths), 109-133.

Moore, J. W., Wegner, D. M., and Haggard, P. (2009). Modulating the sense of agency with external cues. Conscious. Cogn. 18, 1056-1064 doi: 10.1016/j.concog.2009.05.004

Morsella, E. (2005). The function of phenomenal states: supramodular interaction theory. Psychol. Rev. 112, 1000-1021. doi: 10.1037/0033295X.112.4.1000

Morsella, E. (2009). “The mechanism of human action: introduction and background," in Oxford Handbook of Human Action, eds E. Morsella, J. A. Bargh, and P. M. Gollwitzer (New York, NY: Oxford University Press), $1-32$.

Morsella, E., and Bargh, J. A (2010). What is an output? Psychol. Inq. 21, 354-370. doi: 10.1080/1047840X.2010.524597

Morsella, E., and Bargh, J. A. (2011) "Unconscious action tendencies: sources of 'un-integrated' action," in The Handbook of Social Neuroscience, eds J. T. Cacioppo and J. Decety (New York, NY: Oxford University Press), 335-347. doi: 10.1093/oxfordhb/9780195342161. 013.0022

Morsella, E., Berger, C. C., and Krieger, S. C. (2011). Cognitive and neural components of the phenomenology of agency. Neurocase 17 209-230. doi: 10.1080/13554794. 2010.504727

Morsella, E., Gray, J. R., Krieger, S. C., and Bargh, J. A. (2009a). The essence of conscious conflict: subjective effects of sustaining incompatible intentions. Emotion 9 717-728. doi: 10.1037/a0017121

Morsella, E., Wilson, L. E., Berger, C. C., Honhongva, M., Gazzaley, A., and Bargh, J. A. (2009b). Subjective aspects of cognitive control at different stages of processing. Atten. Percept. Psychophys. 71, 1807-1824. doi: 10.3758/APP.71.8.1807

Morsella, E., and Miozzo, M. (2002) Evidence for a cascade model of lexical access in speech production. J. Exp. Psychol. Learn. Mem. Cogn. 28 , 555-563. doi: $10.1037 / 0278$ 7393.28.3.555

Most, S. B., Scholl, B. J., Clifford, E. and Simons, D. J. (2005). What you see is what you set: sustained inattentional blindness and the capture of awareness. Psychol. Rev. 112, 217-242. doi: 10.1037/0033295X.112.1.217

Müller, J. (1843). Elements of Physiology. Philadelphia, PA: Lea and Blanchard.

Münsterberg, H. (1891). Über Aufgaben und Methoden der Psychologie. Schriften der Gesellschaft für psychologische Forsschung 1, 93-272.

Nagel, T. (1974). What is it like to be a bat? Philos. Rev. 83, 435-450. doi: $10.2307 / 2183914$

Nattkemper, D., and Ziessler, M. (2004). Editorial: cognitive control of action: the role of action effects. Psychol. Res. 68, 71-73. doi: 10.1007/s00426-003-0145-6

Navarrete, E., and Costa, A. (2004). How much linguistic information is extracted from ignored pictures? Further evidence for a cascade model of speech production. J. Mem. Lang. 53, 359-377. doi: 10.1016/j.jml.2005.05.001

Neisser, U. (1967). Cognitive Psychology. Englewood Cliffs, NJ: Prentice-Hall, Inc.

Neisser, U. (1976). Cognition and Reality: Principles and Implications of Cognitive Psychology. San Francisco, CA: W. H. Freeman Publishing.

Neumann, O. (1987). "Beyond capacity: a functional view of attention," in Perspectives on Perception and Action, eds H. Heuer and A. F. Sanders (Hillsdale, NJ: Lawrence Erlbaum), 361-394.

Newman, J. P., Widom, C. S., and Nathan, S. (1985). Passive avoidance in syndromes of disinhibition: psychopathy and extraversion. J. Pers. Soc. Psychol. 5, 1316-1327. doi: 10.1037/0022-3514.48.5.1316

O'Regan, J. K., and Noë, A. (2001). A sensorimotor account of vision and visual consciousness. Behav. Brain Sci. 24, 939-1031. doi: 10.1017/S0140525X01000115

Ortinski, P., and Meador, K. J. (2004). Neuronal mechanisms of conscious awareness. Arch. Neurol. 61 1017-1020. doi: 10.1001/archneur. 61.7.1017

Pacherie, E. (2008). The phenomenology of action: a conceptual framework. Cognition 107, 179-217. doi: 10.1016/j.cognition. 2007.09.003

Panagiotaropoulos, T. I., Kapoor, V., and Logothetis, N. K. (2013). Desynchronization and rebound of beta oscillations during conscious and unconscious local neuronal processing in the 
macaque lateral prefrontal cortex. Front. Psychol. 4:603. doi: 10.3389/fpsyg.2013.00603.

Panagiotaropoulos, T. I., Deco, G., Kapoor, V., and Logothetis, N. K. (2012). Neuronal discharges and gamma oscillations explicitly reflect visual consciousness in the lateral prefrontal cortex. Neuron 74, 924-935. doi: 10.1016/j.neuron.2012.04.013

Pinker, S. (1997). How the Mind Works. New York, NY: Norton.

Posner, M. I. (1980). Orienting of attention. Q. J. Exp. Psychol. 32, 3-25. doi: 10.1080/00335558008248231

Proffitt, D. R. (2013). An embodied approach to perception: by what units are visual perceptions scaled? Perspect. Psychol. Sci. 8, 474-483. doi: 10.1177/1745691613 489837

Proffitt, D. R., Stefanucci, J., Banton, T., and Epstein, W. (2003). The role of effort in perceiving distance. Psychol. Sci. 14, 106-112. doi: 10.1111/1467-9280.t01-1-01427

Puttemans, V., Wenderoth, N., and Swinnen, S. P. (2005). Changes in brain activation during the acquisition of a multifrequency bimanual coordination task: from the cognitive stage to advanced levels of automaticity. J. Neurosci. 25, 4270-4278. doi: 10.1523/JNEUROSCI.3866-04.2005

Raymond, J. E., Shapiro, K. L., and Arnell, K. M. (1992). Temporary suppression of visual processing in an RSVP task: an attentional blink? J. Exp. Psychol. Hum. Percept. Perform. 18, 849-860. doi: 10.1037/0096-1523.18.3.849

Repp, B. H., and Knoblich, G. (2007). Action can affect auditory perception. Psychol. Sci. 18, 6-7. doi: 10.1111/j.1467-9280.2007.01839.x

Rizzolatti, G., Sinigaglia, C., and Anderson, F. (2008). Mirrors in the Brain: How Our Minds Share Actions, Emotions and Experience. New York, NY: Oxford University Press.

Roach, J. (2005). Journal ranks top 25 unanswered science questions. Natl Geogr. News. Available online at: news.nationalgeographic.com (Accessed on June 30, 2005).

Rosenbaum, D. A. (2002). "Motor control," in Stevens' Handbook of Experimental Psychology: Vol. 1. Sensation and Perception, 3rd Edn., series eds H. Pashler (series ed.) and S. Yantis, (volume ed.) (New York, NY: Wiley), 315-339.

Rosenbaum, D. A. (2005). The Cinderella of psychology: the neglect of motor control in the science of mental life and behavior.
Am. Psychol. 60, 308-317. doi: 10.1037/0003-066X.60.4.308

Roser, M., and Gazzaniga, M. S. (2004). Automatic brainsinterpretive minds. Curr. Dir. Psychol. Sci. 13, 56-59. doi: 10.1111/j.0963-7214.2004.00274.X

Rossetti, Y. (2001). "Implicit perception in action: short-lived motor representation of space," in Finding Consciousness in the Brain: A Neurocognitive Approach, ed P. G. Grossenbacher (Amsterdam: John Benjamins Publishing), 133-181.

Sato, A. (2009). Both motor prediction and conceptual congruency between preview and action-effect contribute to explicit judgment of agency. Cognition 110, 74-83. doi: 10.1016/j.cognition. 2008.10.011

Schacter, D. L. (1996). Searching for Memory: The Brain, the Mind, and the Past. New York, NY: Basic Books.

Schacter, D. L., and Addis, D. R. (2007). The cognitive neuroscience of constructive memory: remembering the past and imagining the future. Philos. Trans. R. Soc. Lond. $B$ Biol. Sci. 362, 773-786. doi: 10.1098/rstb.2007.2087

Schütz-Bosbach, S., and Prinz, W. (2007). Perceptual resonance: action-induced modulation of perception. Trends Cogn. Sci. 11, 349-355. doi: 10.1016/j.tics.2007.06.005

Sergent, C., and Dehaene, S. (2004). Is consciousness a gradual phenomenon? evidence for an all-or-none bifurcation during the attentional blink. Psychol. Sci. 15, 720-728. doi: 10.1111/j.09567976.2004.00748.x

Shallice, T. (1972). Dual functions of consciousness. Psychol. Rev. 79, 383-393. doi: 10.1037/h0033135

Sheerer, E. (1984). "Motor theories of cognitive structure: a historical review," in Cognition and Motor Processes, eds W. Prinz and A. F. Sanders (Berlin: Springer-Verlag), 77-98. doi: 10.1007/978-3-64269382-3_6

Sherrington, C. S. (1900). "The muscular sense," in Textbook of Physiology, ed E. A. Schafer (Edinburgh: Pentland), 1002-1025.

Sherrington, C. S. (1906). The Integrative Action of the Nervous System. New Haven, CT: Yale University Press.

Simon, J. R., Hinrichs, J. V., and Craft, J. L. (1970). Auditory S-R compatibility: reaction time as a function of ear-hand correspondence and earresponse-location correspondence. J. Exp. Psychol. 86, 97-102. doi: $10.1037 / \mathrm{h} 0029783$
Simpson, G. G. (1949). The Meaning of Evolution. New Haven, CT: Yale University Press.

Sobel, N., Prabhakaran, V., Hartley, C. A., Desmond, J. E., Glover, G. H., Sullivan, E. V., et al. (1999). Blind smell: brain activation induced by an undetected air-borne chemical. Brain 122, 209-217. doi: 10.1093/brain/122.2.209

Sperry, R. W. (1952). Neurology and the mind-brain problem. Am. Sci. 40, 291-312.

Sperry, R. W. (1961). Cerebral organization and behavior: the split brain behaves in many respects like two separate brains, providing new research possibilities. Science 133, 1749-1757. doi: 10.1126/science.133.3466.1749

Squire, L. R. (1987). Memory and Brain. New York, NY: Oxford University Press.

Srinivasan, R., Russell, D. P., Edelman, G. M., and Tononi, G. (1999). Increased synchronization of neuromagnetic responses during conscious perception. J. Neurosci. 19 , 5435-5448.

Stroop, J. R. (1935). Studies of interference in serial verbal reactions. J. Exp. Psychol. 18, 643-662. doi: 10.1037/h0054651

Suzuki, T., Itoh, S., Arai, N., Kouno, M., Noguchi, M., Takatsu, M., et al. (2012). Ambient echolalia in a patient with germinoma around the bilateral ventriculus lateralis: a case report. Neurocase 18, 330-335. doi: 10.1080/13554794.2011.608364

Synofzik, M., Vosgerau, G., and Lindner, A. (2009). Me or not me: an optimal integration of agency cues. Conscious. Cogn. 18, 1065-1068. doi: 10.1016/j.concog. 2009.07.007

Synofzik, M., Vosgerau, G., and Newen, A. (2008a). I move, therefore I am: a new theoretical framework to investigate agency and ownership. Conscious. Cogn. 17, 411-424. doi: 10.1016/j.concog.2008.03.008

Synofzik, M., Vosgerau, G., Newen, A. (2008b). Beyond the comparator model: a multifactorial two-step account of agency. Conscious. Cogn. 17, 219-239. doi: 10.1016/j.concog.2007.03.010

Tallon-Baudry, C. (2012). On the neural mechanisms subserving attention and consciousness. Front. Psychol. 2:397. doi: 10.3389/fpsyg. 2011.00397

Taylor, J. A., and Ivry, R. B. (2013). "Implicit and explicit processes in motor learning," in Action Science, eds W. Prinz, M. Beisert, and A. Herwig (Cambridge, MA: The MIT Press), 63-87.
Taylor, J. L., and McCloskey, D. I. (1990). Triggering of preprogrammed movements as reactions to masked stimuli. J. Neurophysiol. 63, 439-446.

Taylor, J. L., and McCloskey, D. I. (1996). Selection of motor responses on the basis of unperceived stimuli. Exp. Brain Res. 110, 62-66. doi: 10.1007/BF00241375

Tononi, G. (2012). Phi: A Voyage from the Brain to the Soul. New York, NY: Pantheon.

Tononi, G., and Edelman, G. M. (1988). Consciousness and complexity. Science 282, 1846-1851. doi: 10.1126/science.282.5395.1846

Treisman, A. M., and Gelade, G. (1980). A feature-integration theory of attention. Cogn. Psychol. 12, 97-136. doi: 10.1016/0010-0285 (80)90005-5

Tsakiris, M., Schütz-Bosbach, S., and Gallagher, S. (2007). On agency and body-ownership: phenomenological and neurocognitive reflections. Conscious. Cogn. 16, 645-660. doi: 10.1016/j.concog.2007.05.012

Uhlhaas, P. J., Pipa, G., Lima, B., Melloni, L., Neuenschwander, S., Nikolic, D., et al. (2009). Neural synchrony in cortical networks: history, concept and current status. Front. Integr. Neurosci. 3:17. doi: 10.3389/neuro.07.017.2009

van Veen, V., Cohen, J. D., Botvinick, M. M., Stenger, V. A., and Carter, C. C. (2001). Anterior cingulate cortex, conflict monitoring, and levels of processing. Neuroimage 14, 1302-1308. doi: 10.1006/nimg.2001.0923

Varela, F., Lachaux, J. P., Rodriguez, E., and Martinerie, J. (2001). The brainweb: phase synchronization and large-scale integration. National Review of Neuroscience 2, 229-239. doi: 10.1038/35067550

Washburn, M. F. (1928). "Emotion and thought: a motor theory of their relation," in Feelings and Emotions: The Wittenberg Symposium, ed C. Murchison (Worcester, MA: Clark University Press), 99-145.

Watson, J. B. (1924). Behaviorism. New York, NY: W. W. Norton.

Wegner, D. M. (2002). The Illusion of Conscious Will. Cambridge, MA: MIT Press.

Wegner, D. M. (2003). The mind's best trick: how we experience conscious will. Trends Cogn. Sci. 7, 65-69. doi: 10.1016/S1364-6613 (03)00002-0

Wegner, D. M., and Bargh, J. A. (1998). "Control and automaticity in social life," in The Handbook of Social Psychology, 4th Edn., Vol. 1 and 2, 
eds D. T. Gilbert, S. T. Fiske, and G. Lindzey (New York, NY: McGrawHill), 446-496.

Wegner, D. M., and Wheatley, T. P. (1999). Apparent mental causation: sources of the experience of will. Am. Psychol. 54, 480-492. doi: 10.1037/0003-066X.54.7.480

Weiskrantz, L. (1992). Unconscious vision: the strange phenomenon of blindsight. Science 35, 23-28.

Weiskrantz, L. (1997). Consciousness Lost and Found: A Neuropsychological Exploration.
New York, NY: Oxford University Press.

Witt, J. K., Proffitt, D. R., and Epstein, W. (2005). Tool use affects perceived distance but only when you intend to use it. J. Exp. Psychol. Hum. Percept. Perform. 31, 880-888. doi: 10.1037/0096-1523.31.5.880

Wohlschläger, A. (2000). Visual motion priming by invisible actions. Vis. Res. 40, 925-930. doi: 10.1016/S0042-6989(99)00239-4

Zeki, S., and Bartels, A. (1999). Toward a theory of visual consciousness.
Conscious. Cogn. 8, 225-259. doi: 10.1006/ccog.1999.0390

Received: 13 August 2013; accepted: 15 August 2013; published online: 10 September 2013.

Citation: Morsella $E$ and Poehlman TA (2013) The inevitable contrast: Conscious vs. unconscious processes in action control. Front. Psychol. 4:590. doi 10.3389/fpsyg.2013.00590

This article was submitted to Cognition, a section of the journal Frontiers in Psychology.
Copyright (C) 2013 Morsella and Poehlman. This is an open-access article distributed under the terms of the Creative Commons Attribution License (CC BY). The use, distribution or reproduction in other forums is permitted, provided the original author(s) or licensor are credited and that the original publication in this journal is cited, in accordance with accepted academic practice. No use distribution or reproduction is permitted which does not comply with these terms. 